\section{Extended Major Histocompatibility Complex Haplotypes in Type I Diabetes Mellitus}

\author{
Donald Raum, Zuheir Awdeh, Edmond J. Yunis, \\ Chester A. Alper, and Kenneth H. Gabbay \\ Center for Blood Research; Departments of Medicine, Pediatrics, \\ and Pathology, Harvard Medical School; Beth Israel Hospital; \\ Dana-Farber Cancer Institute and Children's Hospital \\ Medical Center, Boston, Massachusetts 02115
}

A type I diabetes mellitus and their families. The frequencies of extended haplotypes that were composed of specific HLA-B, HLA-DR, BF, C2, C4A, and C4B allelic combinations, which occurred more commonly than expected, were compared on random diabetic and normal chromosomes in the study families. We demonstrated that all of the previously recognized increases in HLA-B8, B18, B15, DR3, and perhaps DR4 could be ascribed to the increase among diabetic haplotypes of a few extended haplotypes: [HLA B8, DR3, SC01, GLO2]; [HLA-B18, $D R 3, F 1 C 30$ ]; [HLA-B15, DR4, SC33]; and [HLA-BW38, $D R 4, S C 21]$. In fact, HLA-DR3 on nonextended haplotypes was "protective", with a relative risk considerably $<1.0$. There was a paucity or absence among diabetic patients of several extended haplotypes of normal chromosomes, notably [HLA-B7, DR2, SC31] and [HLA$B W 44, D R 4, S C 30]$. The extended haplotype [HLA$B W 38, D R 4, S C 21]$ is found only in Ashkenazi Jewish patients, which suggests that extended halplotypes mark specific mutations that arise in defined ethnic groups.

The data show that no known MHC allele, including $H L A-D R 3$ and possibly $H L A-D R 4$, is per se a marker for or itself a susceptibility gene for type I diabetes. Rather, extended haplotypes, with relatively fixed alleles, are either carriers or noncarriers of susceptibility genes for this disease. Thus, the increased frequency (association) or the decreased frequency (protection) of individual MHC alleles is largely explainable by these extended haplotypes.

Received for publication 2 February 1983 and in revised form 5 April 1984.

\footnotetext{
J. Clin. Invest.

(C) The American Society for Clinical Investigations, Inc. $0021-9738 / 84 / 08 / 0449 / 05 \$ 1.00$
}

Volume 74, August 1984, 449-454

\section{Introduction}

Associations of markers of the major histocompatibility complex (MHC) ${ }^{1}$ with type I diabetes mellitus have been amply documented. The incidence of HLA-B8, HLA-B18, HLA-B15, HLADW3/DR3, and HLA-DW4/DR4 is increased in Caucasian patients with type I diabetes mellitus, while the incidence of HLAB7 and HLA-DW2/DR2 is decreased (1-8). Of the other markers encoded within or close to the MHC, the incidence of $B F * F 1$, a rare allele of the locus for properdin factor $\mathrm{B}$, and $C 4 B * 3$, an allele of one of the $\mathrm{C} 4$ genetic loci, are also increased in insulindependent diabetes mellitus (IDDM) $(9,10)$. However, there is no difference between type I diabetic patients and controls in the frequencies of types of glyoxalase I (GLO) (11), which is a protein encoded by a genetic locus that is also on the short arm of chromosome 6 but nearer the centromere than the MHC. The genes for the complement proteins factor $\mathrm{B}(B F), \mathrm{C} 2(C 2)$, and $C 4(C 4 A$ and $C 4 B)$ are closely linked to one another without known crossovers. The four gene complement haplotypes are inherited as single genetic units which are called complotypes. We previously identified 14 common and distinct complotypes in normal Caucasians (12) and showed that they are closely linked to $H L A-D R$ (13). HLA-B, DR, and complotype combinations with significant linkage disequilibrium among normal chromosomes were defined as extended haplotypes (14).

It has been suggested that the markers that confer the highest relative risks for type I diabetes, particularly HLA-DR3 and HLA-DR4, are primary indicators of, or are themselves directly involved in, the initial pathogenesis of pancreatic $\beta$ cell destruction $(15,16)$. In this view, the other markers at the HLA-B locus $(B 8, B 18$, and $B 15)$ are secondarily increased because of the known linkage disequilibria in Caucasians of $H L A-B 8$ and $B 18$ with $H L A-D R 3$, and $H L A-B 15$ with $H L A-D R 4$ (17). In an earlier study, the association of haplotypes that contained these alleles to type I diabetes was shown, and the authors concluded

1. Abbreviations used in this paper: $\mathrm{BF}, \mathrm{C} 2, \mathrm{C} 4 \mathrm{~A}$, and $\mathrm{C} 4 \mathrm{~B}$, complement proteins factor B, C2, C4; GLO, glyoxalase I: IDDM, insulin-dependent diabetes mellitus; MHC, major histocompatibility complex. 
that these associations were due to several susceptibility loci that were linked to specific HLA alleles (18).

In the present study, we analyzed MHC markers (HLA-A, B, C, DR, BF, C2, C4A, C4B, and GLO) in families of type I diabetic patients, and defined extended haplotypes with specific sets of alleles of HLA, complement, and GLO loci. The extended haplotypes occur with different frequencies among patient and normal chromosomes, and allow the differentiation of more specific associations of certain extended haplotypes with susceptibility genes of type I diabetes than is possible for individual alleles (e.g., $H L A-D R 3, D R 4$, or $B F * F 1$ ). The findings rule out all of the hitherto identified individual HLA or complement genes, including $H L A-D R 3$, as the primary susceptibility genes for type I diabetes mellitus. This may also be true of HLA-DR4, although the current data for HLA-DR4 are not definitive.

\section{Methods}

Patients. We studied type I diabetes mellitus in Caucasian patients, their parents, siblings, and other relatives that participated in the Diabetes Control and Vascular Disease Study at the Children's Hospital Medical Center (19). All patients had onset of disease before $20 \mathrm{yr}$ of age. Of the 19 randomly ascertained families, only one had more than one affected sib, although patients in three families had affected cousins who were also studied. If a haplotype occurred in one or more patients in a family, it was considered "diabetic", whereas if it did not occur in a patient, but only in healthy relatives, it was considered "normal." A second group of 20 families were ascertained because they had a diabetic patient known to carry BF F1 or BF S1. Families with patients who carried BF F1 were selected in order to better define other MHC markers on $B F * F I$-bearing haplotypes in a North American type I diabetes population of varied European ethnicity. As in the study of randomly selected diabetic families, haplotypes that did not occur in patients were considered random normal, whereas the non $B F * F 1$-containing haplotypes in these patients or their diabetic sibs were considered "random diabetic" and were pooled with the diabetic haplotypes that were ascertained randomly. Haplotypes that occurred in $>1$ person in a family were counted only once. Fig. 1 demonstrates a hypothetical family in which two children have type I diabetes mellitus. Their genotypes are B18, DR3, FIC30, $G L O 2 / B 8, D R 3, S C 01, G L O 2$, and B15, DR4, SC33, GLO2/B18, DR3, $F 1 C 30, G L O 2$. If this family had been ascertained for BF F1, then the $B 18, D R 3, F 1 C 30, G L O 2$ chromosome would not have been counted in calculating frequencies in the random "diabetic" group. The other two chromosomes, $B 8, D R 3, S C 01, G L O 2$ and $B 15, D R 4, S C 33, G L O 2$, were classified as "diabetic" and the chromosome B18,DR2,SC31, GLOI as normal. In this way, 61 random diabetic and 74 normal haplotypes were determined in the families in this study. In addition, we used 448 other normal control haplotypes from previous studies (14). Table I shows that the frequencies of representative $D R$ and $G L O$ alleles in these $\mathbf{4 4 8}$ normal haplotypes do not differ significantly from the $\mathbf{7 4}$ normal haplotypes from diabetic families.

Use of the normal haplotypes from the families under study obviated the potential ethnic variations between random normal and random diabetic haplotypes. To determine whether this population of normal haplotypes in families with patients with type I diabetes was similar to our larger population of normal Caucasian chromosomes (14), for which the ethnicity was not carefully determined but which was approximately similar to that of the study population, the frequencies of HLA-DR

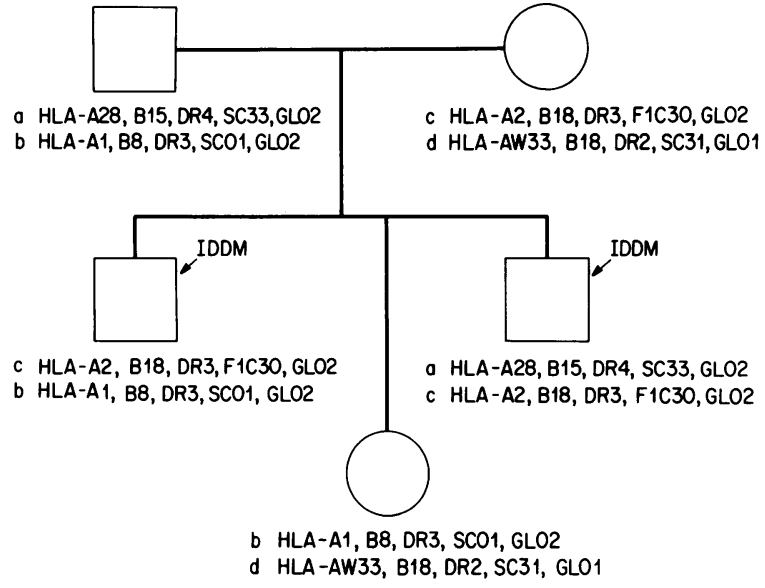

Figure 1. A hypothetical pedigree of a family ascertained for BF F1 that demonstrates how haplotypes were classified as normal or "diabetic". Two children (IDDM) have type I diabetes. Their genotypes are B18,DR3, F1C30,GLO2/B8, DR3, SC01, GLO2 and B15, DR4, $S C 33, G L O 2 / B 18, D R 3, F 1 C 30, G L O 2$. Since the family was ascertained for BF F1, the B18, DR3, F1C30, GLO2 chromosome was excluded from the "diabetic" group. The two chromosomes, B8, DR3, SC01, GLO2 and B15, DR4, SC33, GLO2 were classified as "diabetic", and the chromosome B18, DR2, SC31, GLO1 was called normal.

(Table I) and common extended haplotypes were compared by the $\chi^{2}$ test. There were no significant differences (all $P>0.05$ ).

$B F, C 2$, and $C 4$ typing. Fresh or freshly frozen $\left(\right.$ at $\left.-70^{\circ} \mathrm{C}\right)$ serum or EDTA plasma samples were subjected to agarose gel electrophoresis at pH 8.6 and immunofixation with goat antiserum to human factor $B$ (Atlantic Antibodies, Scarborough, ME) for BF typing (20). For C2 types, the same samples were analyzed by isoelectric focusing in polyacrylamide gels (21) and then an overlay of agarose gel that contained antibody-sensitized sheep erythrocytes and human serum diluted 1:90 in isotonic Veronal-buffered saline, $\mathrm{pH} 7.4$, which contained $0.1 \%$ gelatin, $10^{-3} \mathrm{M} \mathrm{Mg}^{++}$, and $1.5 \times 10^{-4} \mathrm{M} \mathrm{Ca}^{++}$. Portions of the same samples were treated with Clostridium perfringens neuraminidase (Sigma Chemical Co., St. Louis, MO) at $10 \mathrm{U} / \mathrm{ml}$ for $15 \mathrm{~h}$ at $4^{\circ} \mathrm{C}$ before agarose gel electrophoresis at $\mathrm{pH} 8.6$ and crossed immunoelectrophoresis for detection of half-null C4 haplotypes (22), or to agarose gel electrophoresis at $\mathrm{pH}$ 8.6, and immunofixation with anti-C4 (Atlantic Antibodies), for detection of structural variants of $C 4 A$ and $C 4 B$ (23). Complotypes are given in arbitrary order as $\mathrm{BF}, \mathrm{C} 2, \mathrm{C} 4 \mathrm{~A}$, and $\mathrm{C} 4 \mathrm{~B}$ types run together, with "0" for Q0 (null) alleles (12).

GLO typing. Red cell lysates were spotted on cellulose acetate, and electrophoresis was performed in a $0.03 \mathrm{M}$ Tris, $0.03 \mathrm{M}$ barbituric acid, $0.2 \mathrm{mM}$ mercaptoethanol, $0.4 \mathrm{mM} \mathrm{MgCl}_{2}$ buffer, $\mathrm{pH} 8.0$, at $200 \mathrm{~V}$ for $1 \mathrm{~h}$ or until albumin had run $10 \mathrm{~cm}$. Plates were stained first with 0.02 $\mathrm{M}$ glutathione and $0.34 \mathrm{M}$ methylglyoxal in a $0.1-\mathrm{M}$ phosphate buffer, $\mathrm{pH} 6.5$, and then with $0.1 \mathrm{mM}$ 3-[4,5-dimethylthiazolyl-2]-2,5-diphenyltetrazolium bromide, $0.69 \mathrm{mM}$ 2,4-dichlorophenolindophenol in a $0.1 \mathrm{M}$ Tris hydrochloride buffer at $\mathrm{pH} 7.8$ (24).

$H L A-A, B, C$, and DR typing. Routine typing was performed using a modification of the National Institutes of Health Standard Microlymphocytotoxicity Test procedure. 140 antisera were used for defining 19 A-locus, 28 B-locus, and 6 C-locus antigens. Routine HLA-DR typing 
Table I. Allele Frequencies in Normal Control, Normal Family, and Diabetic Chromosomes

\begin{tabular}{|c|c|c|c|c|c|c|c|c|c|c|}
\hline Population & No. & DR1 & DR2 & DR3 & DR4 & DR5 & DRW6 & DR7 & GLOI & GLO2 \\
\hline Normal controls & $448(373)^{*}$ & 0.09 & 0.15 & 0.14 & 0.16 & 0.15 & 0.10 & 0.13 & 0.39 & 0.61 \\
\hline \multicolumn{11}{|l|}{ Normal chromosomes from } \\
\hline diabetic families & $74(67)$ & 0.11 & 0.20 & 0.11 & 0.18 & 0.16 & 0.04 & 0.11 & 0.33 & 0.67 \\
\hline Type I diabetes chromosomes & $61(56)$ & 0.13 & 0.02 & 0.30 & 0.39 & 0.07 & 0.0 & 0.08 & 0.32 & 0.68 \\
\hline
\end{tabular}

* Haplotypes with available GLO are given in parentheses.

was performed using the technique of the Oxford (7th International Histocompatibility) Workshop, Oxford, England (25). 70 antisera (40 reference and 30 local) were used for defining seven HLA-DR antigens.

\section{Notes on $C 4$ nomenclature}

Confusion has arisen concerning the name of the HLA-B15-associated $C 4 B$ allele. In this paper it is denoted as $C 4 B * 3$, as suggested by an international committee (26). This committee has defined the allele associated with HLA-BW47 as $C 4 B * 31$ (26). Others have denoted the latter allele as $C 4 B * 3$ and the one associated with $H L A-B 15$ as $C 4 B * 2.9$ $(27,28)$. The original paper, which noted the association of this allele with HLA-B15 in diabetes called it $C 4 B * 4$ (29). We have previously referred to the $H L A-B 15$-associated $C 4 B$ allele on normal chromosomes as $C 4 B * 3$ in our discussion of this extended haplotype (14). The current accepted designation for the $H L A-B 15$-associated $C 4 B$ allele is $C 4 B * 3$.

\section{Results}

From the study of 18 randomly ascertained families with diabetic patients, 39 haplotypes occurred in patients and were defined as random type I diabetes mellitus haplotypes. An additional 22 random diabetic haplotypes were obtained from 20 families that were ascertained for BF F1 or BF S1. From the remaining haplotypes in these families (i.e., those not occurring in known diabetic patients) and from the nonpatient haplotypes that occurred in families selected for BF S1 or BF F1, 74 normal haplotypes were also defined.

Fig. 2 shows an analysis of these random diabetic and normal haplotypes that were classified according to DR types. The upper portion of the Fig. $2 \mathrm{~A}$ shows the absolute frequencies of haplotypes of different DR types among the diabetic and two kinds of normal chromosomes. Diabetic haplotypes are at the left, and normal haplotypes from diabetic families are in the center, and haplotypes from overall control families are to the right of each set of bars in Fig. 2. Nonextended haplotypes are shown in the crosshatched areas, and known extended haplotypes are shown within each bar. There were no significant differences in the frequencies of extended haplotypes among diabetic normals and all normals, and this excludes population stratification or other trivial mechanisms as causes for the findings in diabetics.

The well known increase in $H L A-D R 3$ and $D R 4$ and the decrease in $D R 2$ among diabetic patients' chromosomes is evident. The entire increase in $H L A-D R 3$ is the result of the increase in two extended haplotypes: [ $H L A-B 8, D R 3, S C 01]$ (haplotypes
$\mathrm{C}+\mathrm{D})$ and $[H L A-B 18, D R 3, F 1 C 30](\mathrm{E})$. There is no increase in randomly associating non-extended $H L A-D R 3$-bearing chromosomes. The increase in $H L A-D R 4$ is both in nonextended and extended haplotypes. The decrease in HLA-DR2 is in both the known $D R 2$ extended and nonextended haplotypes. There were no instances of $[H L A-B 7, D R 2, S C 31]$ in diabetic patients.

Remarkably, the increase in [HLA-B8, DR3,SCO1] is entirely in the GLO2-bearing chromosome. In fact, there is no increase in the GLOI-bearing chromosome in IDDM patients as com-

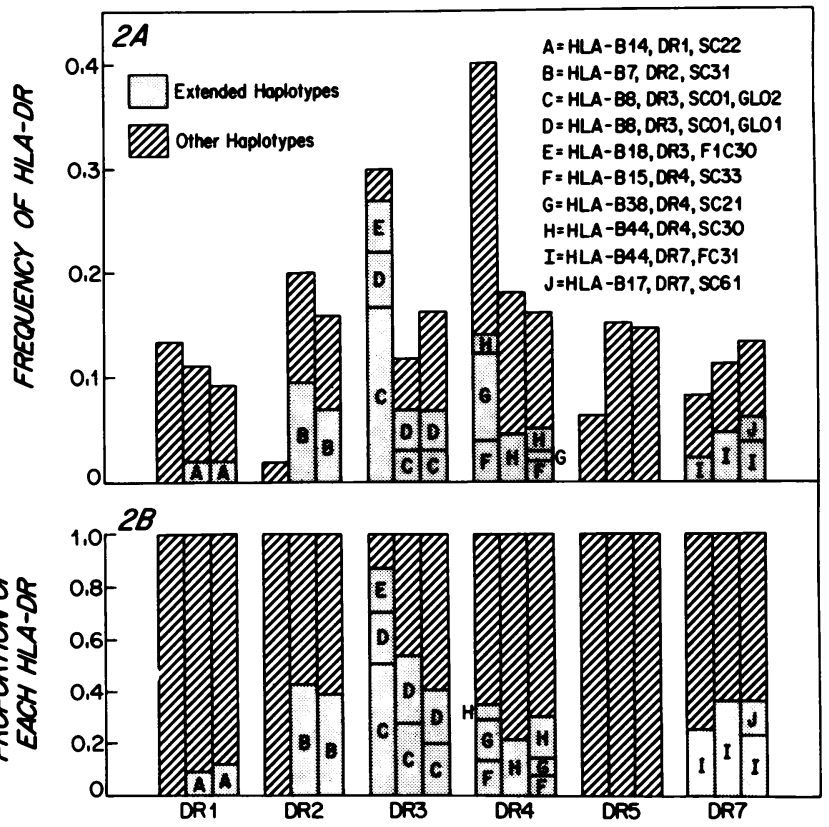

Figure 2. The frequencies of HLA-DR alleles are shown in a population of type I diabetes patients. For each HLA-DR allele the bar on the left is the frequency in the diabetics, while the bar in the center is the frequency of these alleles in the same families but not associated with disease, and the bar on the right is the frequency of these alleles in all normals. Within each bar, extended haplotypes are denoted by stippled areas and are labelled as A, B, C, etc. These correspond to the labeled haplotypes in the upper right hand corner. Fig. $2 A$ shows the absolute frequency of these alleles, while in Fig. $2 B$ the frequencies of extended haplotypes are normalized to the frequency of each HLA-DR allele. 
pared with normal (Fig. $2 A$ ). The increase in proportion of the $G L O 2$ to $G L O 1$-bearing [HLA-B8, DR3, SCO1] extended haplotype among patient chromosomes (9:3 of 56 who were GLO typed), compared with our previously determined normal chromosomes (14:16 of 405 of complete haplotypes with GLO), was significant $\left(\chi^{2}=16.52, P<0.00005\right)$. These differences are reflected by a relative risk of 5.3 for the [HLA-B8,DR3, SCO1, $G L O 2]$ haplotype, whereas that of the same haplotype but with $G L O 1$ is 1.0 (no significantly increased relative risk). Conversely, the risk for DR3 on nonextended haplotypes compared with extended haplotypes is 0.23 , and compared with all diabetic haplotypes is 0.71 , which clearly excludes DR 3 per se as causative in type I diabetes.

The increase in $H L A-D R 4$ among diabetic chromosomes is seen from Fig. $2 A$ to be contributed to by increases in frequency of $[H L A-B 15, D R 4, S C 33]$ and [HLA-BW38, DR4, SC21]. There is no increase, but in fact a significant decrease $(P=0.05$, by Poisson distribution), in the incidence of the most common extended haplotype with $D R 4$ in normals, [HLA-BW44, DR4, $S C 30]$. We had not previously recognized [HLA-BW38, DR4, $S C 21]$ as an extended haplotype in normals. In the present study, all instances of this haplotype (five diabetic and two normal) were with HLA-A26, and all occurred in Ashkenazi Jews. Unlike $H L A-D R 3$, there was a general increase in nonextended $H L A-D R 4-$ bearing haplotypes among diabetic chromosomes. However, in both normal and disease $H L A-D R 4$-bearing haplotypes, the majority of chromosomes did not carry currently identified extended haplotypes.

To determine if there was a general increase in $H L A-B 18$, $B 8$, or $B 15$, the frequency of these alleles on haplotypes other than extended haplotypes was determined. The frequency of $H L A-B 18$ not associated with $D R 3$ and $B F * F 1$ among patient haplotypes was found to be $\mathbf{0 . 0 6 5}$, compared with a frequency among all normal chromosomes (none of which had F1C30) of 0.042 . Similarly, the frequency of $H L A-B 8$ was 0.032 on nonextended patient haplotypes, and 0.04 on normal nonextended haplotypes. $H L A-B 15$ did not occur on nonextended haplotypes among diabetic chromosomes and had a frequency of 0.027 among normal chromosomes. Thus, there was no general increase in $H L A-B 8, H L A-B 18$, or $H L A-B 15$ among type I diabetic chromosomes that were unassociated with extended haplotypes. Therefore, all increases in these alleles (HLA-B8, $B 18, B 15)$ in diabetic patients are ascribed to the noted extended haplotypes. There was a striking decrease in HLA-DR2 in patients, which was associated with a marked decrease in both randomly associating nonextended $D R 2$-bearing haplotypes, as well as with the absence of the extended haplotype [HLA-B], $D R 2, S C 31]$ in diabetic patients.

In the selected diabetic haplotypes with the rare BF variant $F 1$ (significantly increased among diabetic patients), $B F * F 1$ was on chromosomes whose HLA-A alleles were $A W 30$ (40\%), $A 2$ (31\%), $A 28(20 \%)$, and other $H L A-A(13 \%)$. Most (80\%) were $H L A-B 18$, although one each were $B W 35, B W 49, B 14$, or $B W 21$. In every case, $B F * F 1$ was part of the complotype $F 1 C 30$. There was no striking difference between the distribution of GLO types in diabetic patients with this haplotype (GLO1 $=0.37$, $\mathrm{GLO} 2=0.63)$ and the overall control population $(0.38$ and 0.62 ). Thus, $B F * F 1$ marked an extended haplotype, [HLA-B18, $D R 3, F 1 C 30$ ], with moderate variation at HLA-A and GLO.

Fig. $2 B$ shows the proportional frequency of each haplotype within its DR. Direct comparisons between the relative distributions of specific extended and nonextended haplotypes among patient and normal chromosomes are thus possible. The differences in composition of $H L A-D R 3$ haplotypes between diabetics and normals are even more striking (e.g., the increase in $[H L A-B 18, D R 3, F 1 C 30]$, the decrease in $[H L A-B 8, D R 3$, $S C 01, G L O 1]$, and the increase in $[H L A-B 8, D R 3, S C 01$, $G L O 2])$. The proportion of nonextended haplotypes for $H L A$ $D R 3$ is clearly less in diabetic than normal chromosomes. Similarly, the absence of the $[H L A-B 7, D R 2, S C 31]$ and decrease in the $[H L A-B W 44, D R 4, S C 30]$ extended haplotypes are notable.

\section{Discussion}

It is clear from these results that the previously observed increases in HLA-B8, B18, B15, HLA DW3/DR3, DW4/DR4, and BF $F 1$ in Caucasian type I diabetic patients are largely the result of the increased frequencies of a few extended haplotypes which bear the corresponding alleles. These extended haplotypes have been identified in populations of normal Caucasian chromosomes and are defined as specific combinations of HLA-B, DR, and complotype alleles in significant linkage disequilibrium (14). Most of these occur at frequencies of at least 0.01 among normal chromosomes. Among diabetic chromosomes we have identified the following extended haplotypes that are present in increased frequency as compared with normal: [HLA-B8, DR3, SCO1, GLO2], [HLA-B18, DR3, F1C30], [HLA-B15, DR4, SC33], and $[H L A-B W 38, D R 4, S C 21]$. Moreover, we have identified two extended haplotypes that are "protective," i.e., are absent from diabetic chromosomes or occur at significantly lower frequencies than among normal chromosomes. These extended haplotypes are $[H L A-B 7, D R 2, S C 31]$ and $[H L A-B W 44, D R 4$, $S C 30]$. In addition, DR3 on nonextended haplotypes had a relative risk $<1.0$ and was therefore also protective. Thus, with the possible exception of $D R 4$ (because we may not recognize all extended haplotypes of low frequency), no single MHC allele, including $H L A-D R 3$, is in itself a susceptibility gene, nor can its product be directly involved in the initial pathogenesis of pancreatic $\beta$ cell destruction as has been postulated by others $(15,16)$. This is also consistent with the finding that $H L A-D$ $\beta$-chain restriction fragment length polymorphisms in genomic DNA differ between $H L A-D R$-identical healthy and insulindependent diabetic individuals (30).

A corollary of a model that assigns a simple primary role for the HLA-DR alleles is that the proportions of individual extended haplotypes would be the same among $H L A-D R 3$ and $D R 4$ haplotypes in patient and normal chromosomes. Our data 
show that this is not the case. The most striking deviation is the unexpected finding that the GLO1/GLO2 ratio among [ $H L A$ $B 8, D R 3, S C 01]$ haplotypes in type I diabetes as compared with normal chromosomes is reversed. Thus, two very similar haplotypes, both carrying the known diabetic markers $H L A-B 8$ and $D R 3$, which were distinguished only by their GLO types, differ radically in conferring susceptibility to diabetes. GLO per se is, of course, not a marker for type I diabetes mellitus, as shown in this and previous studies $(11,31)$. Kirk et al. (11) reported the frequencies of GLO1 and GLO2 in type I diabetes population to be 0.44 and 0.56 , and in normals to be 0.44 and 0.56 . McCann et al. (31) reported frequencies of 0.54 and 0.47 for GLO1 and GLO2 in type I diabetic patients, and 0.45 and 0.55 in normals. Among our type I diabetes patients the frequencies of GLO1 and GLO2 were 0.32 and 0.68 , and in normals 0.38 and 0.62 , which confirmed $\left(\chi^{2}=0.7, P\right.$ NS) these previous studies.

Although the HLA-DR3 increase in type I diabetes is largely explained by the increased frequency of two $H L A-D R 3$-marked extended haplotypes, it should be noted that most of $H L A-D R 3$ haplotypes are extended in patients and normal subjects. Such is not the case for $H L A-D R 4$-bearing haplotypes in patients and normals of which the bulk are nonextended. The increase in DR4-bearing haplotypes in diabetics is in both extended and nonextended haplotypes, which suggests the possibility that DR4 per se is linked to or is itself a susceptibility gene for type I diabetes. However, the most common DR4-bearing extended haplotype, $[B 44, D R 4, S C 30]$, is decreased among diabetic chromosomes, and thus makes this less likely. Moreover, it may be that there are a large number of yet unidentified $D R 4$ - or $D R 2$-bearing extended haplotypes that occur in low frequency in either or both populations of chromosomes.

The extended haplotypes appear to mark separate mutations that arise in distinct ethnic groups. The haplotype $H L A-(A W 30)$, $B 18, D R 3, B F F 1$, which is common in Frenchmen (32) and Basques, is markedly increased among Basque diabetic patients (33). This extended haplotype, with our additional definition of the complotype as F1C30, has also been found in our diabetic population. There is also an increased frequency in our study of [HLA-(A26), BW38,DR4,SC21] but only among Ashkenazi Jewish patient chromosomes. The haplotype is present on normal chromosomes from the same ethnic group in our study and had previously been partly recognized as $H L A-A 26, B W 38$ in diabetic patients of the same ethnicity in Israel (34). These findings suggest that the extended MHC haplotypes, with increased frequencies in Caucasian type I diabetic patients in North American populations, mark separate mutations in distinct, previously isolated ethnic groups. Because the frequency of the postulated type I diabetes susceptibility gene must be high (between 0.01 and 0.15 ), it is to be expected that any extended haplotype bearing such a gene would be common in the normal population. This is true in our study. In contrast, the [HLA$B W 47, D R 7, F C 0,31, G L O 1]$ haplotype, which marks $>20 \%$ of 21-hydroxylase deficiency chromosomes (35), is rare. The disease gene has a frequency of $<1 \%$, although it is fully pen- etrant, and the extended haplotype marking it is rare $(\leq 0.003)$ in the normal population.

We have previously suggested that some extended haplotypes mark murine t-like analogues in man (36). Wild mouse populations frequently carry mutant genes on chromosomes 17 (the chromosome that bears the murine $\mathrm{MHC}$ ) called the $\mathrm{T} / \mathrm{t}$ complex. These mutants are lethal in the homozygote and are usually transmitted by the male to almost all of his offspring. The $T / t$ complex, which includes the MHC, is associated with crossover suppression in meioses which involve mutant and wild chromosomes. Crossover suppression and male transmission bias, if they occur in human analogues of $t$-mutants, would produce extended haplotypes. We suggested that $t$-analogues would function as genetic sinks and collect a variety of deleterious mutations, including susceptibility genes to various disorders, which include type I diabetes. We also presented evidence that the $[H L A-B 8, D R 3, S C 01, G L O 2]$ haplotype has at least one feature of murine t-mutants and shows a male transmission bias of $>0.8(14,37)$. This view predicts that $[H L A-B 8, D R 3$, $S C 01, G L O 2]$ would be increased specifically in type I diabetes as compared with the GLO1 marked haplotype, which is consistent with our findings.

Our concept of extended haplotypes $(14,36)$ suggests that if a disease susceptibility gene is carried on such a haplotype, it will be on many, if not all, instances of such haplotypes and its frequency would be elevated on patient chromosomes. On the other hand, if such haplotypes lack susceptibility genes, their frequency will be markedly lowered among patient chromosomes. Examples of such "protective chromosomes" in our study would include [HLA-B7, DR2,SC31], [HLA-BW44, DR4, $S C 30]$, and perhaps other haplotypes such as [HLA-BW57,DR7, $S C 61]$ and $[B W 61, D R W 6, S C 02]$.

\section{Acknowledgments}

We thank Dr. Jay Sosenko, Dr. Grace Banuchi, and Stephanie Schwartz, R.N., for their help. Expert technical assistance was provided by Debbie Marcus, Sylvia Fluckiger, Vivian Katz, Sharon Karp, Rosanne Stein, Sharon Martin Alosco, and Tanya Evelson.

This work was supported by grants AM 26844, CA 20531, CA 06516, HL 29583, HL 20539 (HL 32327), and AM 15019 (AM 34077), from the National Institutes of Health, and grants from the Juvenile Diabetes Foundation and the American Red Cross.

\section{References}

1. Singal, D. P., and M. A. Blajchman. 1973. Histocompatibility antigens, lymphocytotoxic antibodies and tissue antibodies in patients with diabetes mellitus. Diabetes. 22:429-432.

2. Nerup, J., P. Platz, D. Ortved Andersen, M. Christy, J. Lyngsoe, J. E. Poulson, L. P. Ryder, L. Staub-Nielsen, M. Thomsen, and A. Svejgaard. 1974. HL-A antigens and diabetes mellitus. Lancet. II:864866.

3. Cudworth, A. G., and J. C. Woodrow. 1976. Genetic susceptibility in diabetes mellitus: Analysis of the HLA association. Br. Med. J. 2:846848. 
4. Ludwig, H., G. Schernthauer, and W. R. Mayr. 1976. Is HLAB7 a marker associated with a protective gene in juvenile-onset diabetes mellitus? N. Engl. J. Med. 294:1066.

5. Van de Putte, I., C. Vermylen, C. Decralne, P. Vlietinick, and R. Van den Berghe. 1976. Segregation of HLA B7 in juvenile onset diabetes mellitus. Lancet. II:251.

6. Cudworth, A. G. 1978. Type I diabetes mellitus. Diabetologia. 14:281-291.

7. Svejgaard, A., P. Platz, and L. P. Ryder. 1980. Insulin-dependent diabetes mellitus. In Histocompatibility Testing. 1980. P. I. Terasaki, editor. Munksgaard, Copenhagen. 638-656.

8. Thomsen, M., P. Platz, D. Ortved Andersen, M. Christy, J. Lyngsoe, J. Nerup, N. Rasmussen, L. P. Ryder, L. Staub-Nielsen, and A. Svejgaard. 1975. MLC typing in juvenile diabetes mellitus and idiopathic Addison's disease. Transplant Rev. 22:125-147.

9. Raum, D., C. A. Alper, R. Stein, and K. H. Gabbay. 1979. Genetic marker for insulin dependent diabetes mellitus. Lancet. I:1208-1210.

10. McCann, V. J., J. McCluskey, P. H. Kay, P. J. Zillio, F. T. Christiansen, and R. L. Dawkins. 1983. HLA and complement genetic markers in diabetic retinopathy. Diabetologia. 24:221.

11. Kirk, R. L., J. Theophilus, S. Whitehouse, J. Court, and P. Zimet. 1979. Genetic susceptibility to diabetes mellitus: the distribution of properdin factor B (Bf) and glyoxalase (GLO) phenotypes. Diabetes. 28:949-951.

12. Alper, C. A., D. Raum, S. Karp, Z. L. Awdeh, and E. J. Yunis. 1983. Serum complement 'supergenes' of the major histocompatibility complex in man (complotypes). Vox Sang. 45:62-67.

13. Raum, D. D., Z. L. Awdeh, D. Glass, E. Yunis, and C. A. Alper. 1981. The location of $C 2, C 4$ and $B F$ relative to $H L A-B$ and $H L A-D$. Immunogenetics. 12:473-483.

14. Awdeh, Z. L., D. Raum, E. J. Yunis, and C. A. Alper. 1983. Extended HLA-complement-glyoxalase allele haplotypes: evidence for T/t-like complex in man. Proc. Natl. Acad. Sci. USA. 80:259-263.

15. Thomsen, G., and W. Bodmer. 1977. The genetic analysis of HLA and disease associations. In HLA and Disease. J. Dausset and A. Svejgaard, editors. Munksgaard, Copenhagen. 84-93.

16. Ryder, L. P., and A. Svejgaard. 1981. Genetics of HLA disease association. Annu. Rev. Genet. 15:169-187.

17. Bodmer, W. F., and J. G. Bodmer. 1978. Evolution and function of the HLA system. Br. Med. Bull. 34:309-316.

18. Contu, L., I. Deschamps, H. Lestradet, J. Hors, M. Schmid, M. Busson, A. Benajam, A. Marcelli-Barge, and J. Dausset. 1982. HLA haplotype study of 53 juvenile insulin-dependent diabetic (I.D.D.) families. Tissue Antigens. 20:123-140.

19. Sosenko, J. M., J. L. Breslow, O. S. Miettinen, and K. H. Gabbay. 1980. Hyperglycemia and plasma lipid levels: a prospective study in young insulin-dependent diabetic patients. N. Engl. J. Med. 302:650654.

20. Alper, C. A., T. Boenisch, and L. Watson. 1972. Genetic polymorphism in human glycine-rich beta-glycoprotein. J. Exp. Med. 135:6880.

21. Alper, C. A. 1976. Inherited structural polymorphism in human C2: evidence for genetic linkage between $\mathrm{C} 2$ and Bf. J. Exp. Med. 144:1111-1115.

22. Awdeh, Z. L., D. Raum, and C. A. Alper. 1979. Genetic polymorphism of the fourth component of human complement: detection of heterozygotes. Nature (Lond.). 282:205-207.
23. Awdeh, Z. L., and C. A. Alper. 1980. Inherited structural polymorphism of the fourth component of human complement (C4). Proc. Natl. Acad. Sci. USA. 77:3576-3580.

24. Kömpf, J., S. Bissbort, S. Gussman, and H. Ritter. 1975. Polymorphism of cell glyoxalase I (E.C:4.4.15). A new genetic marker in man. Humangenetik. 27:141-143.

25. Bodmer, W. F., J. R. Batchelor, J. G. Bodmer, H. Festenstein, and P. J. Morris, editors. 1978. Histocompatibility Testing 1977. Munksgaard, Copenhagen. 612.

26. Mauff, G., C. A. Alper, Z. Awdeh, J. R. Batchelor, J. Bertrams, G. Bruun-Petersen, R. L. Dawkins, P. Démant, J. Edwards, H. GrosseWilde, G. Hauptmann, P. Klouda, L. Lamm, E. Mollenhauer, C. Nerl, B. Olaisen, G. O'Neill, C. Rittner, M. H. Roos, V. Skanes, P. Teisberg, and $\mathrm{L}$. Wells. 1983. Statement on the nomenclature of human C4 allotypes. Immunobiology. 164:184-191.

27. Kay, P. H., J. McCluskey, F. T. Christiansen, D. Feeney, U. J. McCann, P. J. Zilko, R. L. Dawkins, and G. J. O'Neill. 1983. Complement allotyping reveals new genetic markers in rheumatoid arthritis and diabetes mellitus. Tissue Antigens. 21:159-160.

28. McCluskey, J., V. J. McCann, P. H. Kay, P. J. Zilko, F. T. Christiansen, G. J. O'Neill, and R. L. Dawkins. 1983. HLA and complement allotypes in Type I (insulin-dependent) diabetes. Diabetologia. 24:162-165.

29. Bertrams J., U. Hintzen, V. Schlicht, and S. Schoeps. 1982. C4: another marker for Type I diabetes. Lancet. I:41. (Letter.)

30. Owerbach, D., Å. Lernmark, P. Platz, P. Ryder, L. Rask, P. A. Peterson, and J. Ludvigsson. 1983. HLA-D region beta-chain DNA ribonuclease fragments differ between HLA-DR identical healthy and insulin-dependent diabetic individuals. Nature (Lond.). 303:815-817.

31. McCann, V. J., R. E. Davis, T. A. Welborn, I. J. Constable, and D. G. Beale. 1981. Glyoxalase phenotypes in patients with diabetes mellitus. Aust. N.Z. J. Med. 11:380-382.

32. Dausset, J., L. Legrand, V. Lepage, L. Contu, A. Marcelli-Barge, I. Wildloecher, A. Benajam, T. Meo, and L. Degos. 1978. A haplotype study of HLA complex with special reference to the HLA-DR series and to $\mathrm{Bf}, \mathrm{C} 2$ and glyoxalase I polymorphisms. Tissue Antigens. 12:297307.

33. de Mouzon, A., E. Ohayon, J. Ducos, and G. Hauptmann. 1979. BF and C4 markers for insulin-dependent diabetes in Basques. Lancet. II: 1364 .

34. Bonné-Tamir, B., J. G. Bodmer, W. F. Bodmer, P. Pickbourne, C. Brautbar, E. Gazit, S. Nevo, and R. Zamir. 1978. HLA polymorphism in Israel 9. An overall comparative analysis. Tissue Antigens. 11:235250 .

35. Fleischnick, E., Z. L. Awdeh, D. Raum, J. Granados, S. M. Alosco, J. F. Crigler, Jr., P. S. Gerald, C. M. Giles, E. J. Yunis, and C. A. Alper. 1983. Extended MHC haplotypes in 21-hydroxylase-deficiency congenital adrenal hyperplasia: shared genotypes in unrelated patients. Lancet. I:1269-1275.

36. Alper, C. A., Z. L. Awdeh, D. D. Raum, and E. J. Yunis. 1982. Extended major histocompatibility complex haplotypes in man: role of alleles analogous to murine t mutants. Clin. Immunol. Immunopathol. 24:276-285.

37. Awdeh, Z. L., D. Raum, E. J. Yunis, A. Katz, K. H. Gabbay, and C. A. Alper. 1983. Male transmission bias of a human chromosome 6p. Ninth $A A C H T$. In press. (Abstr.) 